\title{
O SABER E A TECNOLOGIA: MITOS DE UM CENTRO DE TRATAMENTO INTENSIVO
}

Marisa Antonini Ribeiro Bastos ${ }^{2}$

Bastos MAR. O saber e a tecnologia: mitos de um centro de tratamento intensivo. Rev Latino-am Enfermagem 2002 março-abril; 10(2):131-6.

O presente artigo apresenta os resultados de um estudo etnográfico que teve como objetivo descrever a cultura dos enfermeiros de um centro de tratamento intensivo. Acreditando que o CTI é uma subcultura do hospital e que os enfermeiros intensivistas compartilham de símbolos e significados que foram desenvolvidos através das interações sociais no contexto da Terapia Intensiva, fui buscar no interacionismo simbólico e na descrição etnográfica a fundamentação teórico-metodológica para o presente estudo. Para compreender o processo de interiorização dos universos simbólicos no CTI, busquei descrever os sistemas temáticos de significados subjacentes às atividades dos enfermeiros intensivistas, através da observação participante, da entrevista etnográfica e da análise documental. Dentre os elementos culturais descritos, foi identificado o mito do saber e da tecnologia. Concluí que os mitos da tecnologia e do saber foram socialmente estabelecidos como estratégia de sobrevivência no cotidiano da terapia intensiva, repleto de riscos e incertezas.

DESCRITORES: cultura organizacional, unidades de terapia intensiva, enfermagem

\section{KNOWLEDGE AND TECHNOLOGY: MITHS IN AN INTENSIVE CARE CENTER}

This article is a partial result of an ethnographic study that had the purpose to describe the culture of intensive care unit nurses. Considering that the ICU is a subculture of the hospital, and that the professionals share symbols and meanings that were developed through social interactions in the context of Intensive Care, the symbolic interactionism and the ethnographic description were used as a theoretical and methodological basis for this study. The participant observation, the ethnographic interview and the documented analysis were used to understand the process of internalization of the symbolic universe of the ICU. Among the described cultural elements, authors identified knowledge and technology myths. They conclude that knowledge and technology myths were socially established as a survival strategy in the daily routine of intensive care full of risks and uncertainty.

DESCRIPTORS: organizational culture, intensive care center, nursing

\section{EL SABER Y LA TECNOLOGÍA: MITOS DE UN CENTRO DE TRATAMIENTO INTENSIVO}

El presente artículo muestra los resultados parciales de un estudio etnográfico que tuvo como objetivo describir la cultura de los enfermeros de un centro de tratamiento intensivo(CTI). Aceptando que el CTI es una subcultura del hospital y que los enfermeros intensivistas comparten símbolos y significados que fueron desarrollados a través de interacciones sociales en el contexto de la Terapia Intensiva, busqué en el interaccionismo simbólico y en la descripción etnográfica la fundamentación teórico-metodológica para el presente estudio. Para comprender el proceso de interiorización de los universos simbólicos en el CTI describí los sistemas temáticos de significados subyacentes a las actividades de los enfermeros intensivistas, a través de la observación participante, de la entrevista etnográfica y del análisis documental. Dentro de los elementos culturales descritos se identificaron el mito del saber y el de la tecnología. Se concluye que los mitos del saber y de la tecnología fueron socialmente establecidos como estrategias de sobre vivencia en la cotidianidad de la terapia intensiva, que está repleta de riesgos e incertidumbre.

DESCRIPTORES: cultura organizacional, unidades de terapia intensiva, enfermería

\footnotetext{
${ }^{1}$ Projeto financiado pela FAPEMIG; ${ }^{2}$ Doutor. Professor Adjunto do Departamento de Enfermagem Básica da Escola de Enfermagem da Universidade Federal de Minas Gerais. Endereço: Rua: Patagônia, 500 - Ap. 101 - Sion - 30320-080 - Belo Horizonte - Minas Gerais - Brasil
} 


\section{O FOCO ETNOGRÁFICO}

Quando comecei a trabalhar no Centro de Tratamento Intensivo (CTI), tinha todos os mitos, conceitos, medos e sentimentos característicos de uma estranha àquela cultura.

Logo nos primeiros meses de trabalho no $\mathrm{CTI}$, uma questão me inquietou: o constante e indiscriminado uso da tecnologia no processo diagnóstico-terapêutico de pacientes internados naquele setor, intermediando, de forma significativa, a relação profissional/ paciente. Essa tecnologia, cada vez mais utilizada na assistência ao paciente crítico, tem influenciado não só o significado do trabalho dos profissionais de saúde, como também é encarada como a solução para todos os problemas do paciente ${ }^{(1-2)}$.

Com o significado de eficiência e qualidade nem sempre comprovadas ou mesmo avaliadas, a tecnologia atua como legitimadora do ato do profissional de saúde e da instituição que a adota, passando até mesmo a ser utilizada como critério de avaliação de qualidade dos serviços de saúde prestados pelos hospitais ${ }^{(1)}$.

No entanto, alguns autores adotam uma postura críticoreflexiva diante da mesma. Na ótica desses autores, na busca da racionalização, da aquisição e da incorporação de novas tecnologias, é necessária uma avaliação, sob o ponto de vista ético, dos custos, da qualidade da assistência, dos benefícios, das limitações, dos riscos e da adequação às necessidades da população( ${ }^{(3-10)}$.

Assim, meu interesse voltou-se para a prática dos intensivistas que atuam num contexto altamente tecnológico, com características peculiares relativas ao ambiente físico, social, cultural, psicológico; tipo de assistência prestada; dinâmica do setor e densidade tecnológica da assistência.

Busquei compreender como essa assistência com alta incorporação tecnológica se expressa no contexto da Terapia Intensiva, descrevendo os universos simbólicos compartilhados pelos seus atores e os mecanismos de manutenção dessa cultura.

Os aspectos da prática desses profissionais focalizados no estudo foram identificados no decorrer do processo de pesquisa. No entanto, tracei algumas questões básicas que nortearam, a princípio, meu foco de atenção. Dentre elas:

- Quais são os valores; crenças, mitos e tabus compartilhados pelos intensivistas?

- Qual o significado do saber e da tecnologia na subcultura dos intensivistas?

0 presente artigo apresenta parte dos resultados encontrados em um estudo etnográfico que teve como objetivo descrever a cultura dos intensivistas de um hospital universitário ${ }^{(11)}$.

Os dados apresentados neste artigo estão relacionados ao significado do saber e da tecnologia para os intensivistas do cenário cultural estudado.

\section{A OPÇÃO METODOLÓGICA}

Na escolha de um método de pesquisa, "não há como dissociar a sua dimensão social e política de sua dimensão técnica". A visão de mundo do pesquisador, suas concepções sobre a realidade e a natureza humana estão intimamente articuladas à escolha da metodologia adequada para descrevê-las e compreendê-las ${ }^{(12)}$.

"10-0 estudo de campo é um lugar de aprendizagem contínua. Na medida em que os estudos de cultura procuram lidar com o simbólico, o pesquisador deve estar sempre próximo às interações de que emerge o simbólico. Isso significa que 0 pesquisador deve estar preparado para passar bastante tempo no campo-local de pesquisa, interagindo com os participantes, a fim de aprender com eles sobre a cultura da organização.

$2^{\circ}$-A abordagem e a análise dos dados devem ser interagentes, isto é, o pesquisador não parte para o campo com idéias pré-concebidas, ou com uma série de hipóteses já estabelecidas; ao contrário, o acúmulo de conhecimento surge a partir das interações com os participantes da organização.

$4^{\circ}$-É importante focalizar a atenção nas formas de expressão e na linguagem, porque é através delas que se tem acesso ao universo simbólico ${ }^{(12), "}$.

Assim, optei por realizar um estudo etnográfico, uma vez que é adequado para compreender a complexidade dos fenômenos culturais da organização, sob a perspectiva de seus próprios membros.

A etnografia, inicialmente utilizada para descrever culturas exóticas, constitui um instrumento fundamental para a compreensão de nossa própria cultura e suas especificidades. É o caminho para a compreensão das diferenças culturais, da diversidade própria dos seres humanos ${ }^{(13)}$.

A etnografia é o trabalho de descrição de uma cultura a partir da visão de mundo de seu nativo, buscando a compreensão do significado de ações e eventos para os participantes, expressos através da linguagem, ou indiretamente, através de ações, constituindo-se num sistema de significados complexos que constitui a cultura. A etnografia é situada como uma estratégia teóricometodológica para descobrir os símbolos de uma cultura e compreender suas relações dentro de um complexo sistema de significados $^{(13)}$.

O cenário cultural e as estratégias metodológicas

O estudo foi realizado em um CTI de um hospital universitário de grande porte, em Belo Horizonte.

Os dados foram coletados através de observação participante, entrevistas etnográficas e análise de documentos, tais 
como: normas e rotinas do setor, registro em prontuários, livros, periódicos, com o objetivo de complementar informações obtidas pelas outras técnicas e contextualizar os aspectos históricos do setor.

Foi, também, utilizada a fotografia como recurso de coleta de informações, com o objetivo de ilustrar algumas cenas do cotidiano da terapia intensiva.

As fases da observação participante constituíram-se, na prática, em três fases principais, ou seja, $1^{\circ}$ observação; $2^{\circ}$ observação com pequena participação e $3^{\circ}$ observação com participação moderada. No entanto, é importante relatar que não foi possível identificar uma nítida delimitação entre essas fases.

Os registros etnográficos decorrentes da observação participante foram de natureza descritiva e reflexiva. As descrições foram relativas ao ambiente físico, comportamentos, ações, atividades específicas do setor e diálogos.

Os registros de natureza reflexiva foram relativos às reflexões quanto a questões metodológicas ou teóricas que surgiram no decorrer da pesquisa e que necessitavam de esclarecimento ou elaboração de questões descritivas ou estruturais.

Foram realizadas 14 entrevistas etnográficas com 12 informantes, sendo dois considerados fundamentais devido a algumas características básicas: eram antigos funcionários do setor, tendo um rico conhecimento cultural; mostraram-se altamente receptivos à participação como informantes e, principalmente, tiveram uma compreensão imediata do que eu buscava apreender e do meu papel de aprendiz cultural.

As entrevistas foram constituídas, inicialmente, de questões descritivas, seguidas de questões estruturais e de contraste. As entrevistas foram gravadas com o objetivo de, após transcrição dos relatos, facilitar a codificação e análise etnográficas.

Os dados foram analisados de forma simultânea à coleta de dados, num processo contínuo de descoberta de questões que seriam utilizadas nas próximas entrevistas etnográficas.

Os dados coletados através da observação participante foram utilizados para a contextualização da cena cultural em estudo e na complementação e/ou validação das informações, sendo coletados pelas outras técnicas adotadas.

Foram realizadas análises de domínio, taxonômica, componencial e temática, implicando uma volta contínua às anotações de campo e registro das entrevistas etnográficas. Foi, também, realizada uma abordagem de inventário, no sentido de construir um modelo das interações simbólicas da subcultura estudada ${ }^{(13)}$.

Com o objetivo de garantir o rigor científico e confiabilidade dos resultados, foram estabelecidas as seguintes estratégias:

a) Validação dos domínios, taxonomias e paradigmas durante toda a fase de coleta de dados. No final da pesquisa, os informantes checaram também os resultados. b) Questionamento pelos pares: algumas análises foram discutidas com enfermeiros e outros profissionais de saúde com experiência na área de Terapia Intensiva e na abordagem etnográfica.

Foram identificadas algumas peculiaridades em se fazer observação participante numa unidade de assistência a pacientes graves, como, por exemplo, a dificuldade em observar atividades assistenciais sem nenhum tipo de envolvimento com o paciente ou com o profissional que prestava assistência.

Assim, no desenvolver da etnografia, a grande variação e complexidade de situações encontradas no campo de pesquisa colocaram-me frente a algumas questões éticas.

No enfrentamento dessas questões, adotei alguns princípios éticos pautados nos Princípios de Responsabilidade Profissional da Associação Antropológica Americana (1971) e na Lei 196 CNS, tais como o direito do informante de conhecer os objetivos e resultados do estudo, o respeito aos seus interesses, à sua privacidade e dignidade ${ }^{(13)}$.

Diante de um conflito de interesses entre a pesquisadora $e$ os membros da instituição, optei pela prevalência do interesse dos últimos. O respeito a esse princípio pôde ser identificado na escolha do foco etnográfico, em alguns momentos de observação participante e entrevista etnográfica e na omissão de alguns dados que, embora significativos, poderiam comprometer 0 anonimato dos informantes.

O projeto foi desenvolvido em 1995/1996, quando não existia um Comitê de Ética em pesquisa no Hospital. No entanto, é importante ressaltar que foram garantidos a privacidade, 0 anonimato, a participação voluntária dos informantes e a utilização científica dos resultados.

O trabalho de campo foi desenvolvido de forma revelada, ou seja, com conhecimento, por parte dos participantes, do objetivo geral da pesquisa e da identidade da pesquisadora.

O relatório final foi divulgado entre os participantes da pesquisa.

\section{MITOS DE UM CENTRO DE TRATAMENTO INTENSIVO}

Da análise dos dados emergiram conhecimentos e sentidos compartilhados pelos intensivistas e que foram socialmente estabelecidos. Dentre eles, foram identificados os significados da tecnologia e do saber, que atuam como um mito, uma vez que desempenham o papel de manutenção da cultura no CTI.

O papel de um mito cultural é organizar e sustentar uma cultura. Ele regula, moral e socialmente, um grupo. "Articula-se com a ação e as convicções coletivas"(14).

A criação de um mito é considerada uma estratégia de 
resolução de problemas e faz parte da construção da identidade de uma organização. "São necessários à organização das relações entre os indivíduos"(14).

\section{A tecnologia}

Compreender o significado da tecnologia foi uma das indagações iniciais deste estudo, ao entrar naquela cultura. No entanto, ela não se mostrou como um conceito de relevância para aquele grupo, como eu, anteriormente, acreditava.
Mas agora o mais importante não é a tecnologia no CTI. Eu acho que o mais importante no CTI seria a nossa observação.

Pelo que pude observar e aprender, os informantes consideram a tecnologia como algo importante, mas seu uso não pressupõe, necessariamente, uma assistência de boa qualidade, podendo, às vezes, ser utilizada de forma indiscriminada.

Eu acho que tem hora que ela é usada de forma às vezes indiscriminada. Não é que eu seja contra os recursos tecnológicos. Eu acho que há os momentos para serem usados. Tem hora que eu acho que tem excesso.

\begin{tabular}{|c|c|c|c|c|}
\hline RESULTADOS DO & $\begin{array}{c}\text { RELAÇ̄̃O } \\
\text { PROFSSIONALAPACIENTE }\end{array}$ & $\begin{array}{l}\text { dificultar a relação } \\
\text { dificultar a relaçẫo mais pessoal }\end{array}$ & & \\
\hline $\begin{array}{l}\text { USODA } \\
\text { TECNOLOGIA }\end{array}$ & PROFISSIONAL & $\begin{array}{l}\text { dificultar a manipulaçẫo do paciente } \\
\text { dificultar aproximar-se do paciente } \\
\text { conferir mais poder } \\
\text { confenir mais prestigio } \\
\text { ser o profissional mais valorizado } \\
\text { ser o profissional mais procurado }\end{array}$ & $\begin{array}{l}E \\
N \\
F \\
E \\
R \\
M \\
A \\
G \\
E \\
M\end{array}$ & $\begin{array}{l}\text { facilitar o trabalho } \\
\text { servir de orientaçồ } \\
\text { diminuir o trabalho } \\
\text { valorizar o trabalho }\end{array}$ \\
\hline NO PROCESSO & PACIENTE & $\begin{array}{l}\text { causar ansiedade } \\
\text { lesar menos o paciente } \\
\text { ser benéfica } \\
\text { assustar o paciente }\end{array}$ & & $\begin{array}{l}\text { facilitar sua recuperaçẫo } \\
\text { sertir-se invadido } \\
\text { causar iatrogenias } \\
\text { ajudar }\end{array}$ \\
\hline TERAPÊUTICO & 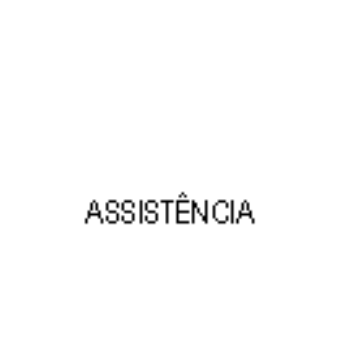 & \multicolumn{3}{|l|}{$\begin{array}{l}\text { poder ser usada indiscriminadamente } \\
\text { nẫo ser o mais importante } \\
\text { ter menos valor que a avaliaçẫo clínica } \\
\text { poder prejudicar } \\
\text { ser fantástica }\end{array}$} \\
\hline
\end{tabular}

Figura 1 - Resultados do uso da tecnologia no processo diagnóstico terapêutico dos pacientes de CTI

Os principais resultados da utilização da tecnologia no processo diagnóstico-terapêutico, sob o ponto de vista dos informantes, estão relacionados ao distanciamento profissional/ paciente, ao aumento de prestígio do profissional que a utiliza na sua prática, à repercussões no paciente e na assistência (Figura1).

Segundo os informantes, a tecnologia facilita o fazer do enfermeiro, valorizando o seu trabalho. Para o paciente, pode causar ansiedade e iatrogenia. No entanto, utilizada no processo diagnósticoterapêutico, pode ser benéfica, ajudar e facilitar a recuperação do paciente.
Nos relatos que se seguem, podem-se observar alguns desses sentidos relacionados na Figura 1.

Às vezes, ele tem um quadro que não exige tanta utilização de aparelhos e já forma uma parafernália em volta dele. Aíjá coloca um monitor de pressão, oxímetro, um monitor disso, daquilo. Eu acho que isso talvez até deva criar uma certa ansiedade no paciente. $E$ eu acho que até dificulta a manipulação, você aproximar do paciente, ter um contato, uma relação mais pessoal com o paciente.

Você sabe, conhecer essas tecnologias dá um certo prestígio, e essas pessoas, por exemplo, as pessoas que detêm o conhecimento de determinadas técnicas, elas são diferenciadas por isso. 
É claro. As pessoas, às vezes, elas valorizam você, mas vão buscar quem? Quem tem experiência naquilo.

Eu acho a tecnologia ótima. No início, quando eu fiz estágio, eram aqueles respiradores horríveis de se manipular. Hoje, não. Você aperta o botão e...É um aparelho que facilitou bastante para a gente. Serve de orientação para o médico. O paciente é menos lesado com isso. Eu acho fantástico. Quanto mais tecnologia que seja para o benefício do paciente, melhor.

Isso assusta o paciente. Mas é só explicar, quando ele está consciente, pra que serve isso, pra que serve aquilo. Ele fica um pouco assustado. Eu acho que ele deve se sentir muito invadido com aquele monte de aparelhagem.

... Para a gente facilita. Por exemplo, a pressão arterial, você não precisa estar lá, toda hora segurando manguito. Eu acho que a tecnologia diminui o trabalho da enfermagem, facilita a recuperação do paciente.

Mas é um movimento muito grande, entra e sai, doentes que saem, morrem. $E$ às vezes tem situações de iatrogenias no CTI.

O saber

Os intensivistas parecem carregar o estigma de donos do saber, auto-suficientes, que podem ser deixados de lado. Mas eles são pessoas vulneráveis como qualquer ser humano, expostos a situações de sofrimento, dor e estresse. Desempenham um papel de capazes de vencer, de dominar a morte, por meio de um saber tecnológico que lhes confere poder, status e prestígio mas que, ao mesmo tempo, encobre seus medos e tensões.

O domínio do saber confere ao intensivista o poder de decidir, de ser o membro do grupo procurado, solicitado e necessário, gerando grande conflito e competitividade entre os intensivistas.

0 poder conferido pelo saber é expresso de diferentes formas, como observado nos relatos abaixo (Figura 2).

O profissional de CTI gosta de ser diferenciado. Ele se acha melhor que os outros em muitas questões. Ele critica o próprio colega. Ele critica demais a posição do outro que não tem a mesma capacidade ou então não tem a mesma carga de informação.

Eu não acho que ele seja diferente em nada, mas a gente nota. É como se o enfermeiro de CTI fosse o todo poderoso, ou fosse uma elite dentro do hospital.

Eles se acham um pouco melhor que os outros. Tem enfermeiro que quer sobressair a todo custo. Eu acho que, no geral, é o mesmo, porque, se me jogarem numa hemodiálise, eu não vou saber nada. Ali, dentro do CTI , a gente lida no dia a dia e cresce no conhecimento. Mas quando você fala:- Trabalho no CTI. Ah! No CTI? É como se fosse uma coisa sobre humana e o que você está fazendo tem uma capacidade além das pessoas.

Você nota que alguns se acham meio elitizados por serem funcionários do CTI. Eles não aceitam ser remanejados.
Tem pessoas assim. Ninguém pode sobressair, saber mais do que elas. Se soubesse era alvo de inveja e de crítica. Isso causa divisão, transtorno entre os enfermeiros.

A gente sente necessidade de melhorar porque, se não, você fica para trás e você é muito criticada pelos próprios colegas. A competitividade é muito grande.

É diferente uma pessoa falar que trabalha no CTI do hospital. Para arrumar emprego, ela tem uma grande facilidade. Dá um status para a pessoa. De alguma maneira ela tem um ganho direto com isso, porque todo mundo considera relevante. Isso é como se fosse um ponto a mais no currículo da pessoa.

É onde a enfermeira tem um domínio muito grande da situação geral. É onde a enfermeira exerce o papel dela e é respeitada também. Eu acho muito importante.

\begin{tabular}{|c|c|}
\hline \multicolumn{2}{|c|}{ TERMOS INCLUSOS } \\
\hline $\begin{array}{l}\text { 0 enfermeiro é muito importante } \\
\text { as pessoas consideram que o } \\
\text { enfermeiro de CTI é mais importante } \\
\text { tem gente que critica o outro que nẫo } \\
\text { tem a mesma capacidade } \\
\text { a gente sente necessidade de } \\
\text { melhorar, senấo fica para tás } \\
\text { quem tem o saber tem o poder } \\
\text { o saber causa divisấo } \\
0 \text { saber causa transtomo entre a } \\
\text { enfermagem } \\
\text { saber algo é motivo de inveja } \\
\text { saber algo é motivo de crịca } \\
\text { a enfermagem no CTI tem mais } \\
\text { poder } \\
\text { o profissional se acha o melhor }\end{array}$ & $\begin{array}{l}\text { é como se fosse uma elite dentro } \\
\text { do hospital } \\
\text { é como se tivesse uma capacidade } \\
\text { além das pessoas } \\
\text { é diferente uma pessoa falar que } \\
\text { trabalha no CTI } \\
\text { a pessoa tem grande facilidade de } \\
\text { arrumar emprego } \\
\text { dá "status" para a pessoa } \\
\text { a pessoa tem um ganho direto } \\
\text { todo mundo considera rele varte } \\
\text { é um ponto a mais no curículo } \\
\text { todo mundo procura a pessoa } \\
\text { a enfermeira é respeitada }\end{array}$ \\
\hline
\end{tabular}

Figura 2 - Formas de se expressar sobre o poder conferido pelo saber

\section{CONCLUSÕES}

No CTI, ambiente onde existe um alto grau de incorporação tecnológica, os profissionais consideram a tecnologia importante, mas não imprescindível, para que o cuidado seja prestado com qualidade. Segundo os intensivistas, a tecnologia "não é a mais importante na assistência", pois pode, às vezes, prejudicar ou ser usada de forma indiscriminada. A tecnologia "tem, sempre, menor valor que a proximidade com o paciente e a sua avaliação clínica".

Segundo os intensivistas, a tecnologia pode dificultar a relação profissional/paciente, às vezes facilitando, às vezes dificultando o seu trabalho. Para o paciente, pode causar iatrogenias, ansiedade e, também, facilitar seu tratamento. 0 saber no CTI confere poder, prestígio, respeito, um ponto a mais no currículo, status e por causa disso, crítica, divisão e transtornos entre a equipe. 0 saber 
estabelece a hierarquia no CTI, onde se dá mais crédito ao enfermeiro que detém o saber do que ao que, oficialmente, é o chefe.

0 enfermeiro que detém o saber é respeitado e procurado pelos antigos e pelo novos membros que logo se dão conta de que é por meio dele que poderão mais facilmente entrar para o mundo dos intensivistas. Ser considerado um deles pressupõe incorporar conhecimentos culturais e técnicos adquiridos pela aproximação ao detentor desses conhecimentos.

\section{REFERÊNCIAS BIBLIOGRÁFICAS}

1. Peixoto MRB. Tecnologia no setor saúde: critérios de avaliação de qualidade dos serviços hospitalares. [dissertação]. Belo Horizonte (MG): Faculdade de Ciências Econômicas/UFMG; 1990.

2. Peixoto MRB. $O$ uso da tecnologia no processo diagnósticoterapêutico: ótica do enfermeiro e do usuário. Rev Esc Enfermagem USP 1994; 28(3):257-69.

3. Fiesta JC. Standards, quality and technology. Nurs Manag 1992; 23(2):16-7.

4. Laupacis A, Feeny D, Detsky AS, Tugwell PX. How atractive does a new technology have to be to warrant adoption and utilization? tentative guiderlines for using clinical and economic evaluations. Can Med Assoc J 1992; 146(4): 473-81.

5. Hard R. Robots: can they help salve the technologist shortage? Hospitals 1991; 65(12): 56-8.

6. Johnsson J. High-tech health care: how much can we afford? Hospitals 1991; 65(16):80.
O conceito de cultura (a gente cria a cultura de se virar sozinho) incorpora o significado das estratégias que um grupo cria para sobreviver num mundo hostil, abandonado, jogado.

O mito do domínio da técnica e do saber é, assim, socialmente estabelecido, como estratégia de sobrevivência de um grupo, num mundo isolado e de sofrimento, onde a máscara do tudo sob controle simula segurança para os outros e para si mesmo, num cotidiano repleto de riscos e incertezas.

7. Halm MA Alpen MA. The impact of technology on patients and families. Nurs Clin North Am1993; 28(2): 443-57.

8. Shortell SM, Zimmerman JE, Rousseau DM, Gillies RR, Wagner $D P$, Diaper EA, et al. The performance of intensive care units: does good management make a difference? Med Care 1994; 32(5): 50825.

9. Walters AJ. Technology and the lifeworld of critical care nursing. J Adv Nurs 1995; 22(2): 338-46.

10. Drought TS, Liaschenko J. Ethical practice in a technological age. Crit Care Nurs Clin North Am 1995; 7(2): 297-304.

11. Peixoto MRB. A prioridade, 0 isolamento e as emoções: estudo etnográfico do processo de socialização em um centro de tratamento intensivo. [tese]. São Paulo (SP): Escola de Enfermagem/USP; 1996. 12. Rodrigues SB. O chefinho, o telefone e "O BODE": autoritarismo e mudança cultural no Setor de Telecomunicações. [tese]. Belo Horizonte (MG): Faculdade de Ciências Econômicas/UFMG; 1991. 13. Spradley J. Participant observation. New York: Holt Rinehart \& Winston; 1980.

14. Chanlat J, organizador. $O$ indivíduo na organização: dimensões esquecidas. São Paulo(SP): Atlas; 1994. 